\title{
Nuclear factor-kB and nitric oxide synthases in red blood cells: Good or bad in obesity? A preliminary study
}

\author{
Monika Široká, ${ }^{1}$ Caterina Franco, ${ }^{2}$ Zuzana Gul'ašová, ${ }^{3}$ Zdenka Hertelyová, ${ }^{3}$ Vladimíra Tomečková, ${ }^{1}$ \\ Luigi F. Rodella, ${ }^{2,4}$ Rita Rezzani ${ }^{2,4}$ \\ ${ }^{1}$ Department of Medical and Clinical Biochemistry, Faculty of Medicine, P.J. Šafárik University, Košice, Slovak Republic \\ ${ }^{2}$ Anatomy and Physiopathology Division, Department of Clinical and Experimental Sciences, University of Brescia, Italy \\ ${ }^{3}$ Department of Experimental Medicine, Faculty of Medicine, P.J. Šafarik University, Košice, Slovak Republic \\ ${ }^{4}$ Interdipartimental University Center of Research "Adaption and Regeneration of Tissues and Organs-(ARTO)", \\ University of Brescia, Italy
}

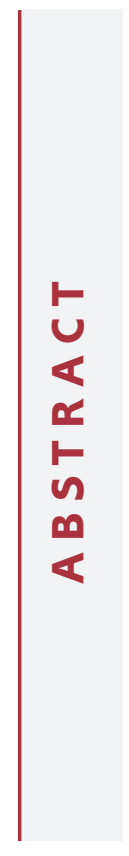

\begin{abstract}
Emerging evidence suggests that red blood cells (RBCs) are involved in many functions essential for life. Nuclear factor-kB (NF-kB), nitric oxide synthases (inducible nitric oxide synthase - iNOS, endothelial nitric oxide synthase - eNOS) and interleukin- $1 \beta$ (IL-1 $\beta$ ) are all proteins that have been identified in RBCs. In nucleated cells, such as white blood cells (WBCs), these proteins have well investigated roles, linked to stress and inflammation. It is not the same in erythrocytes. For this reason, we considered obese patients for studying the morphology of RBCs. We studied a possible correlation between their morphological changes and several protein expressions. Moreover, we compared the results about the aforementioned proteins and antioxidant markers with those obtained in WBCs from healthy and obese patients before and after omega-3 polyunsaturated fatty acid supplementation. This latter scientific point is important in order to determine whether there are differences in the expression of nucleated and anucleated cells. The morphology of RBCs changed in obese patients, but it is significantly restored after six weeks of supplementation. The expression of antioxidant enzymes changed in RBCs and WBCs in obesity but all proteins restore their positivity after supplementation. We found that: the presence of NF-kB, antioxidant enzymes and eNOS in healthy RBCs could indicate a role of these proteins as regulators of cellular metabolism; obese WBCs showed a higher NF-kB, iNOS and IL-1 $\beta$ positivity, whereas eNOS presence did not significantly change in these cells. We tried to explain the different positivity of NF-kB, proposing a dual role for this protein, as prolifespan and as proinflammatory processes, depending on examined cells. In conclusion, we have considered the literature that focuses on the omega6/omega-3 ratio. The ratio changed from the past, especially in people whose diet is strongly westernized worsening the state of health of the patient and leading to an higher incidence of obesity. Our study hypothesizes that the supplementation could help to restore the correct ratio.
\end{abstract}

Key words: Metabolic syndrome; erythrocytes; inflammation; oxidative stress; therapeutic strategies.

Correspondence: Rita Rezzani, Anatomy and Physiopathology Division, Department of Clinical and Experimental Sciences, University of Brescia, Piazza del Mercato 15, 25121 Brescia, Italy.

Tel. +39.030.3717483 - Fax:+39.030.3717486. E-mail: rita.rezzani@unibs.it

Contributions: $\mathrm{ZH}$, realized and wrote the project; ZG, MS, ZH, conceived and planned the clinical trials; $\mathrm{CF}$, ZG, MS carried on the experiments and contributed to the interpretation of the results; ZH, VT, LFR, RR supervised the project; RR wrote the manuscript with input from all Authors. All Authors discussed the results and contributed drafting the final manuscript.

MS and CF contributed equally to this work.

Conflict of interest: The authors declare no conflict of interest.

Funding: This work was supported by $60 \%$ grant (University of Brescia, Italy) and by VEGA and APVV grant (VEGA 1/0584/16; APVV-16-0176) of the Ministry for Education, Science, Research and Sport of the Slovak Republic. Moreover, this publication has been produced thanks to the support of the Operational Program Research and Innovation for the project: Bioactive substances to promote health and prevent chronic diseases (PROBIO-3: NFP313010T651), financed by the European Regional Development Fund.

Ethical approval and consent to participate: This study was conducted in accordance with the Declaration of Helsinki; the Ethical Committee of Faculty of Medicine, Pavol Jozef Šafárik University in Košice, Slovakia, approved it (N. 7N/2016). All the participants provided written consent to participate in the study.

Patient consent for publication: obtained. 


\section{Introduction}

Red blood cells (RBCs) are the most abundant cells in the human body. They were considered only single bags of hemoglobin able to transport up to 1 billion of molecules of oxygen. ${ }^{1}$ Recent evidences suggested that RBCs have many functions essential for life such as the regulation of metabolic homeostasis, hypoxic responses and inflammation; moreover, they participate in the nitric oxide (NO) metabolism. ${ }^{2-6}$ They are also important for their membrane transporters and receptors, that are responsive to drugs, nutraceuticals and phytochemicals. ${ }^{7}$

Many new and unexpected proteins have been identified in these anucleated cells: nuclear factor-kB (NF-kB) and nitric oxide synthases (NOS) are found in RBCs and in platelets, too ${ }^{8-11}$ It is important to emphasize that, in nucleated cells, these proteins have well-investigated roles. ${ }^{12,13}$ In nucleated cells, such as white blood cells (WBCs), in fact, NF-kB regulates the transcriptions of genes involved in apoptosis, the immune responses and inflammation. This factor is engaged in the same inflammatory processes in which it is possible to find also a higher expression of inducible nitric oxide synthase (iNOS) and interleukin $1 \beta$ (IL-1 $\beta$ ). ${ }^{14-19}$ In marked contrast to the other NOS (endothelial nitric oxide synthase - eNOS; neuronal nitric oxide synthase - nNOS), the expression of iNOS in nucleated cells from healthy patients is absent; on the contrary, its expression occurs in metabolic diseases (i.e., obesity and diabetes). ${ }^{20,21}$ Therefore, the activity of iNOS generates significant amounts of $\mathrm{NO}$ and its overproduction is cytotoxic. ${ }^{14,22-24}$ Furthermore, NO-production activity by eNOS diminishes in metabolic diseases. The latter modification is due to insulin resistance, which is mediated and downregulated by NF-kB, and by the free fatty acid induced activation of Toll-like receptor 2 and $4 .^{25,26}$ All the pathways aforementioned have been well investigated in WBCs, where the inflammatory response, especially during obesity, takes place. ${ }^{27}$ Many studies have analyzed changes in the WBC population of obese subjects. Recently, Gu et al, showed that WBC count composition can be used as an important indicator for explaining the complexity of this disease..$^{28}$

Since many of these mediators work as transcription factors, all these proteins have been less considered in anucleated cells because the absence of the nucleus made their presence and their activity obsolete in these cells. ${ }^{2}$ Intriguingly, recent studies related to these proteins took into account also anucleated cells, in particular RBCs and platelets proposing a crucial and non-canonical role for NF-kB since it seems directly involved in the modulation of cell functions and in the promotion of cell survival. ${ }^{8,30}$ Spinelli et al., for example, have demonstrated that inhibitors of NF-kB have profound effects on platelet signaling pathways. ${ }^{8}$ Moreover, Ghashghaeinia et al. showed that other inhibitors of the same protein interfere with the survival of RBCs. ${ }^{30}$ With regard to NOS within RBCs, it has been suggested that they contribute to the intravascular NO pool by regulating physiological functions..$^{31,32}$ Human and mice RBCs have both endothelial (eNOS) and inducible (iNOS) isoforms of NOS. ${ }^{33}$ Much attention has been payed to RBC-eNOS activity suggesting that it regulates RBC deformability. Moreover, NO production by eNOS interacts with target proteins leading to the activation of NO signaling pathways. ${ }^{34}$ However, to our knowledge, there are contradictory and controversial findings on the effective role of iNOS in both nucleated and anucleated cells in clinical and experimental studies. ${ }^{17,31,35-38}$

In support of the non-canonical role of NF-kB and NOS activities, we investigated their expression and the presence of other oxidative markers in RBCs in healthy and obese patients. Obese patients show low levels of antioxidant markers, such as superoxide dismutase-1 (SOD-1) and catalase (CAT), so we used them for defining the inflammatory state characteristic of the condition under examination, as well as IL-1 $\beta$ in WBCs, body mass index (BMI) and triglyceride levels. ${ }^{18,39,40}$ Moreover, we examined the presence of the other proteins in RBCs in healthy and obese patients before and after the supplementation of omega-3 polyunsaturated fatty acid (PUFA). Further, we evaluated the expression of these proteins in RBCs comparing their positivity also with those observed in WBCs using these latter as an example of nucleated cells..$^{41-4}$.

In this study we wanted to underline that NF-kB, could be, also, present in anucleated cells. For years it has been argued that the lack of a transcriptionally active nucleus made proteins with a transcriptional activity obsolete in these cells. For this reason, we decided to compare the expression detected in RBCs with that detected in WBCs.

Next to these considerations we try also to find a way to modulate the changes made by the inflammatory state on RBCs and WBCs. In particular, we considered omega-3, one of two classes of PUFA that are natural components of the diet, having a wide spectrum of physiological roles. ${ }^{44,45}$ This supplementation could play a beneficial role in all the pathologies characterized by an increase in the oxidative state: omega-3 PUFA, in fact, are prone to oxidation, but they are also able to activate the stress-signaling pathways, modulating the response activity of cellular antioxidant enzymes. ${ }^{46}$ Several studies have been carried out even if it is possible to find out conflicting results around PUFA antioxidant effect: these different outcomes could be due to the individual ability to modulate intracellular pro- and anti-oxidant activity regardless of the supplementation. What is relevant is the effect that the supplementation has on the composition of the RBC membrane. When PUFA are introduced, they are incorporated in cell membranes and involved in the maintenance of their composition. ${ }^{47,48}$ It is well-known that fatty acids affect the cell membrane fluidity, the affinity of the receptors, the transport of ions, oxidative stress and inflammatory response, which are associated with cell death or survival. ${ }^{49,50}$ Moreover, this supplementation could help to increase the omega-6/omega-3 ratio that it is reversed in humans as a consequence of agribusiness and modern agriculture..$^{51}$ This last mechanism of action of the supplementation could also be of fundamental importance and indicate a future possible clinical application. In fact, it is well known that this ratio has changed from the past, especially in people whose diet is strongly westernized, and it is also known that an alteration of this ratio worsens the state of health of the patient, predisposing to the development of obesity. The supplementation carried out, therefore, could have a second positive effect also leading to the restoration of the correct ratio.

\section{Materials and Methods}

\section{Study subjects}

This clinical trial involved only the female gender since the global prevalence of obesity is higher in women than in men as reported by Kelly et al. ${ }^{52}$. Moreover, obesity has negative impact on fertility, pregnancy and health of newborn, ${ }^{53,54}$ increases the risk of developing breast and endometrial cancer ${ }^{55,56}$ and is linked to gastroesophageal reflux disease, fatty liver disease and gallstones. ${ }^{57}$

This study was conducted in accordance with the Declaration of Helsinki; the Ethical Committee of Faculty of Medicine, Pavol Jozef Šafárik University in Košice, Slovakia, N. 7N/2016, approved it and defined the samples and the analyses to be carried out within the clinical project. To compensate for potential dropouts, the number of people was increased thanks to the recruitment of volunteers, all from Pavol Jozef Šafárik University in Košice (Slovakia), and their relatives. All the participants provided written consent to participate in the study. 
The study group consisted in 44 women older than 40 years and younger than 60 years; they were involved in the experiment from October 2018 to January 2019. Two participants did not finish the experiment and one participant was excluded at the beginning because of health problems.

Finally, 41 women were divided into 4 groups: eleven healthy subjects (Group 1) and twenty obese patients (Group 2); five obese patients (Group 3) and five obese patients (Group 4) who received respectively three and six weeks of omega-3 PUFA supplementation. All study participants were expressly asked not to introduce further changes in their diet and lifestyle. In this way, the only variable was the introduction of the supplementation under examination in order to assess the effect of this on the parameters evaluated, without any bias.

The number of patients (41 women, aged between 40 and 60 years) has been considered and accepted from Ethical Committee that approved this clinical trial. For healthy subjects the inclusion criteria were: i) aged between 40 and 60 years; ii) BMI higher than $18.5 \mathrm{~kg} / \mathrm{m}^{2}$, but lower than $25 \mathrm{~kg} / \mathrm{m}^{2}$; iii) not pregnant or participants in another clinical trial; iv) not using vitamin-mineral supplement; v) not smoking or abusing alcohol. For obese subjects, the inclusion criteria were: i) aged between 40 and 60 years; ii) BMI higher than $30 \mathrm{~kg} / \mathrm{m}^{2}$; iii) not pregnant or participants in another clinical trial; iv) not using vitamin-mineral supplement; v) not smoking or abusing alcohol. For both healthy and obese subjects, the exclusion criteria were: i) previous oncologic diseases; ii) inflammation diseases; iii) tuberculosis; iv) syphilis; v) renal or hepatic insufficiency; vi) pregnancy.

\section{BMI evaluation}

One of the criteria for dividing the participants into the different groups was the BMI value. ${ }^{58} \mathrm{BMI}$ is calculated using each person's height and weight. The formula for evaluating BMI is BMI = weight $/$ height $^{2}$ or BMI $=\mathrm{kg} / \mathrm{m}^{2}$, where $\mathrm{kg}$ is the person's weight in kilograms and $\mathrm{m}^{2}$ is person's height in meters squared. According to William et al., considering the numeric value of BMI it is possible to recognized four main categories that are summarized in Table $1 .{ }^{58}$

\section{Omega-3 PUFA composition}

Several studies have shown the effectiveness of a supplementation with some natural bioactives such as n-3 PUFAs. Because of their few side effects they may be safer than other modalities for the treatment of different pathological conditions, including also obesity. ${ }^{59}$ This integration could be useful mostly because the human body is able to synthesize many fatty acids, but not linoleic acid (LA; omega-6; C18:2 n-6) or $\alpha$-linolenic acid (ALA; C18:3 n-3), which must be introduced with the diet. ${ }^{59}$ This introduction is even more important if we consider the fact that ALA is the precursor for eicosapentaenoic eicosanoids (EPA, C20:5 n3 ), docosapentaenoic acid (DPA; C22:5 n-3) and DHA (C22:6 n-3) and that the presence of a balanced n-6:n-3 fatty acid ratio (1:1 to $2: 1)$ is important for body homeostasis throughout the lifespan. ${ }^{60}$ For evaluating and defining the best dose of omega-3 PUFA supplementation, several factors have been taken into consideration. First, since that, in women the conversion $\alpha$-linoleic acid to EPA is about $21 \%$ and to DHA is about $9 \%$; the World Health Organization recommends to ingest directly EPA and DHA in food and supplements for increasing the total final contents of these molecules. ${ }^{61,62}$ On the other hand, since the excessive fishing is a global problem and fish oil is the most commonly used source of EPA and DHA, ${ }^{63}$ it could be useful to identify other vegetal sources for obtaining the physiological levels of EPA and DHA, decreasing the dose of omega-3 PUFA administered as fish oil. Other studies also confirmed that supplementation with omega-3 PUFA containing EPA and DHA at the dose of 2-4 g daily decrease triglycerides level, inflammation and platelet aggregation. ${ }^{62}$ For this reason, we decided to integrate the animal omega-3 PUFAs with an additional vegetal source represented by $15 \mathrm{~g}$ of chia seeds (Salvia hispanica L., seeds). Chia seeds, in particular, are important also because they contain important substances for the body, which affect the cardiovascular, immune and nervous systems. ${ }^{64}$

Each fish oil capsule is composed of $225 \mathrm{mg}$ EPA etylesters and $170 \mathrm{mg}$ DHA etylesters and it is provided by MaxiCor ${ }^{\circledR}$, Farmax (Hradec Králové, Czech Republic). The other components of these capsules are: gelatin as packaging; glycerol, vitamin E (DL-alphatocopheryl acetate) as thickener.

About chia seeds (Allnature, s.r.o., Hradec Králové, Czech Republic,) provided them and their composition is guaranteed by brand and tested in laboratory. In particular, they contain $40 \%$ of oil with high content of PUFA and $\alpha$-linoleic acid represents more than $50 \%$ of these acids. Other important ingredients in chia seeds include calcium, potassium, iron, phosphorus, zinc and magnesium. They are also source of proteins (19.0-26.5\%), fibers, vitamins, minerals and antioxidants, suitable for vegans or vegetarians. ${ }^{65}$

Considering all these factors the final daily dose of supplementation was set as 3 capsules of fish oil and $15 \mathrm{~g}$ of chia seeds for a total amount of $675 \mathrm{mg}$ EPA $+510 \mathrm{mg}$ DHA from fish oil and $3 \mathrm{~g}$ of both EPA and DHA from chia seeds.

\section{Blood sample collection and isolation of RBCs}

For all groups, venous blood samples were collected at baseline, after three and six weeks from the beginning of the experiment. Blood smears were collected from participants in the morning after $12 \mathrm{~h}$ fasting, stored into heparin tubes (BD Vacurainer, LH 170 I.U. and BD Vacurainer, K2E - EDTA 10.8 mgM; Plymouth, UK) and used for the analysis of triglyceride levels. Dry blood smears were fixed with cold acetone $\left(4^{\circ} \mathrm{C}\right.$, Sigma-Aldrich, St. Louis, MO, USA) for $10 \mathrm{~min}$ and stored at $-20^{\circ} \mathrm{C}$ according to Thorpe et al. ${ }^{66}$ According to Paździor-Czapula and colleagues and to Esmaeilnejad et al., no other treatments have been done on the smears used for the immunostaining. ${ }^{67} 68$

\section{Quantification of triglyceride levels}

Triglycerides were measured with commercially available kits in an automated biochemical analyzer (RX 63901DAYTONA, Randox Laboratories Ltd., Crumlin, UK). The obtained values were compared with normal range of triglycerides, physiologically between 0.3 and $1.6 \mathrm{mmol} / \mathrm{L} .{ }^{69}$

\section{Morphological evaluation}

Dry blood smears fixed as previously reported were stained with May-Grunwald and Giemsa staining (Bio Optica, Milan, Italy) and then observed using a light microscope (Olympus, Hamburg, Germany) at the final magnification of $1000 x .^{70}$

\section{Immunohistochemistry localization of SOD-1 and CAT, IL-1及, NF-kB, eNOS and iNOS}

Blood smears were washed for $5 \mathrm{~min}$ in tris buffered saline (TBS), then, they were treated for 30 min with $1 \%$ hydrogen peroxide (Sigma-Aldrich) in order to deactivate the endogenous peroxidases in the cells. After washing in TBS, smears were

Table 1. Body Mass Index (BMI) classification.

\begin{tabular}{lc} 
BMII & Weight classes \\
$<18.5$ & Underweight \\
$18.5-24.9$ & Normal weight \\
\hline $25-29.9$ & Overweight \\
$>30.0$ & Obesity \\
\hline
\end{tabular}


preincubated with $1 \%$ bovine serum albumin solution (Sigma Life Science, St. Louis, MO, USA) for $1 \mathrm{~h}$. Then they were incubated for $1 \mathrm{~h}$ at room temperature and subsequently for $30 \mathrm{~min}$ at $37^{\circ} \mathrm{C}$ with the following primary antibodies: mouse monoclonal antibody against SOD-1 (diluted 1:300, Santa Cruz Biotechnology, Inc., Heidelberg, Germany) and goat polyclonal antibody against CAT (diluted 1:200, Santa Cruz Biotechnology, Inc.), mouse monoclonal antibody against IL-1 $\beta$ (diluted 1:200, Santa Cruz Biotechnology, Inc.), rabbit polyclonal antibody against NF-kB-p65 (NF-kB) (diluted 1:200, Abcam, Cambridge, UK), rabbit polyclonal antibody against eNOS (diluted 1:200, Santa Cruz Biotechnology, Inc.) and mouse monoclonal antibody against iNOS (diluted 1:200, Santa Cruz Biotechnology, Inc.). After incubation and washing in TBS, smears were treated respectively with anti-mouse, anti-goat and anti-rabbit secondary antibodies (Vector Laboratories, Inc., Burlingame, CA, USA) for $50 \mathrm{~min}$ at room temperature.

In the end, smears were washed and treated by avidin-biotin complex (Vector Laboratories, Inc.) for $50 \mathrm{~min}$. Finally, smears were stained by 3,3'-diaminobenzidine (DAB, VWR International, LLC, activated by hydrogen peroxide), mounted and observed under light microscopy at final magnification of 1000x (Olympus).

Blood smears without primary antibody and in the presence of isotype-matched IgG served as negative controls.

\section{Semi-quantitative and quantitative analyses}

The immunohistochemical data were evaluated by two blinded observers for semiquantitative and quantitative analysis. In case of dispute concerning interpretation, results were reconsidered to reach a unanimous agreement. The expression of the different proteins has been evaluated in the RBCs and WBCs of each slides stained. Since WBCs were available in the same slides, they were chosen as a representative sample of nucleated cells. For semiquantitative analysis, the results for SOD-1 and CAT, IL-1 $\beta$, NF-kB, eNOS, iNOS, in RBCs and WBCs were expressed as no staining (-), very weak $(+/-)$, weak $(+)$, moderate $(++)$, and strong $(+++)$ positivity. Additionally, we evaluated immunostaining for NF-kB, eNOS and iNOS as Integrated Optical Density (IOD) ${ }^{71}$ In the same way we also evaluated the immunopositivity for SOD-1, CAT and IL-1 $\beta$ expressing it as percentual of positive area on the total area considered (calculated measuring 20 random fields, with the same area $-0.03 \mathrm{~mm}^{2} /$ field - for each smear). In particular, staining intensity was measured considering RBCs and WBCs for each patient, for a total of one hundred RBCs and fifty WBCs randomly selected for each patient. Digitally fixed images of the smears at 1000x magnification were analyzed using an optical microscope (Olympus) equipped with an image analyzer (Image Pro Premier 9.1, MediaCybernetics, Rockville, MD, USA). The Image Pro Premier software generate black and white images for all the pictures used for the immunohistochemical analysis. These black and white pictures could then be used for densitometric analysis, as reported by Reeve and colleagues. ${ }^{72}$ Here the densitometric analysis is considered as a linear inverse scale, ranging from 0 (black) to 250 (white). At the end, all the data were pooled to represent a mean value and statistical analysis were applied to compare the results obtained from the different groups.

\section{Statistical analyses}

The data were pooled to calculate a mean value and results were expressed as the mean \pm standard deviation. Statistical significance of differences among the experimental groups for all the markers was evaluated by analysis of variance (one-way ANOVA) calculated by Origin ${ }^{\circledR}$ 7SRI, 1991-2002 OriginLab Corporation, Northampton, MA, USA) corrected by Bonferroni test with significance set at $\mathrm{P}<0.05$. All the data were evaluated by two blinded observers. In case of dispute concerning interpretation, results were reconsidered to reach a unanimous agreement.

\section{Results}

Differences in triglyceride levels among healthy, obese and obese plus supplementation subjects

In healthy and obese subjects, the mean triglyceride value was respectively $1.505 \mathrm{mmoL} / \mathrm{L}$ and $1.996 \mathrm{mmoL} / \mathrm{L}$ as shown in Figure 1. These values were compared to the normal triglyceride value (see Materials and Methods). Remarkably after six weeks of supplementation, the triglyceride levels showed a significant decrease compared to three weeks of supplementation, converging close to normal levels (Figure 1).

\section{Quantification of triglycerides levels}

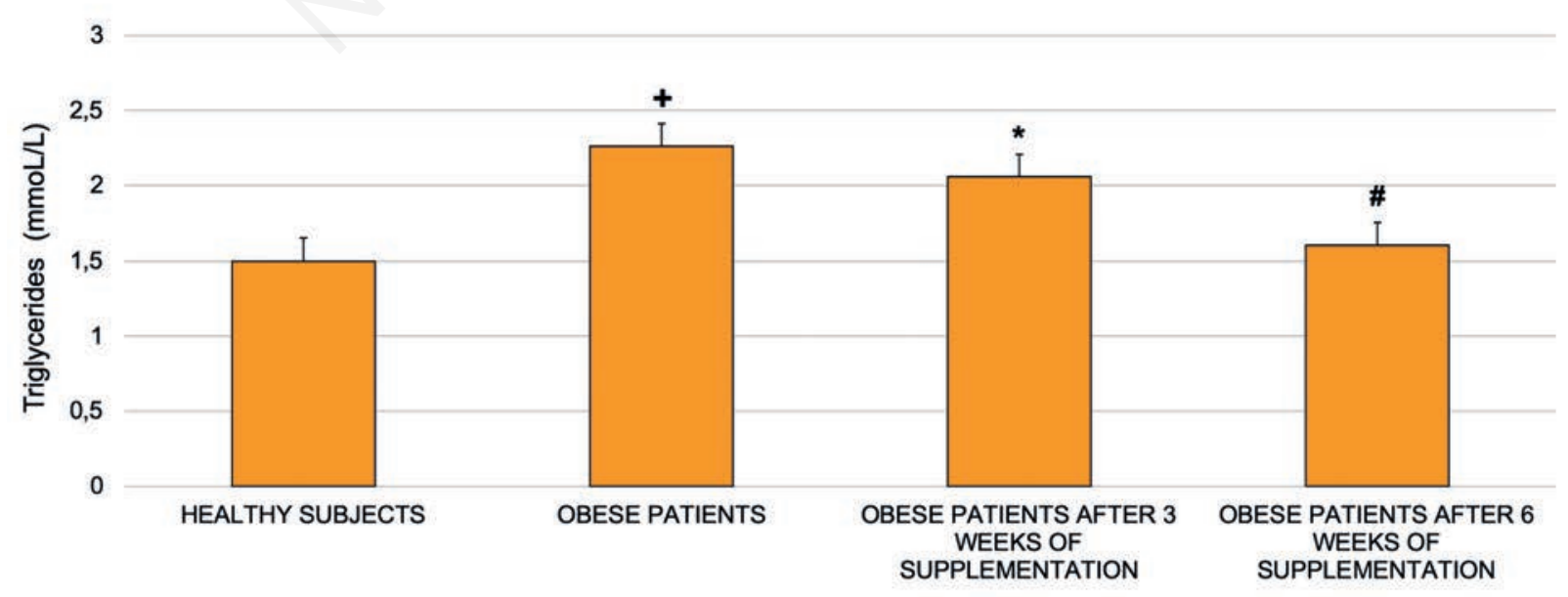

Figure 1. Triglycerides have been evaluated in healthy and obese patients before and after three and six weeks of omega- 3 PUFA supplementation. The results showed a significant decrease in obese subjects after six weeks of omega-3 PUFA supplementation. Bars indicate mean $\pm \mathrm{SD}$. $+\mathrm{P} \leq \mathbf{0 . 0 5}$ vs healthy subjects; $* \mathrm{P} \leq \mathbf{0 . 0 5}$ vs healthy subjects; $\# \mathrm{P} \leq \mathbf{0 . 0 5}$ vs obese subjects. 
Changes of RBC morphology in obesity and its restore with supplementation

We decided to describe the data obtained from the RBCs and WBCs of healthy and obese subjects, and from obese subjects only after six weeks of omega-3 PUFA administration because these findings are more significant than those observed from the same patients after three weeks of supplementation. The results are in line with the biochemical evaluations as reported above allowing to define a link between the inflammatory state, represented by an alteration in the triglycerides levels, and the shape of the RBCs. We have considered these parameters, such as the evaluation of the oxidative state, as possible markers of a different vitality of the cells. Our data also confirmed the one obtained by Seljeflot et al. who have showed that, after six weeks of supplementation, PUFA had improved haemostatic markers of endothelial dysfunction in acute ischemic stroke. ${ }^{73}$

\section{RBC shape alterations}

The RBCs from healthy subjects displayed a normal physiological biconcave-discoid shape (Figure 2A); instead the RBCs obtained from obese patients showed two types of morphological alterations as reported by Ford et $a l .{ }^{74}$ In detail, we found spiculate RBCs with rounded projections (echinocytes) and elongated RBCs forming teardrop-shaped cells with variable surfaces (dacrocytes) (Figure 2B). Interestingly, after supplementation, there was a significant reduction in echinocytes and dacrocytes (Figure 2C).

The statistical analysis of the physiological and altered RBC morphology is shown in Figure 3. In particular, the number of altered shapes is higher for dacrocytes than for echinocytes.

SOD-1 and CAT expression and change of their positivity after omega-3 PUFA supplementation

\section{Red blood cells}

SOD-1 and CAT enzymes were present in RBCs in both healthy and obese subjects although to a lesser extent in obese individuals. In fact, RBCs of healthy and obese subjects were moderately and weakly positive for SOD-1 respectively (Figure 4 A,B). After

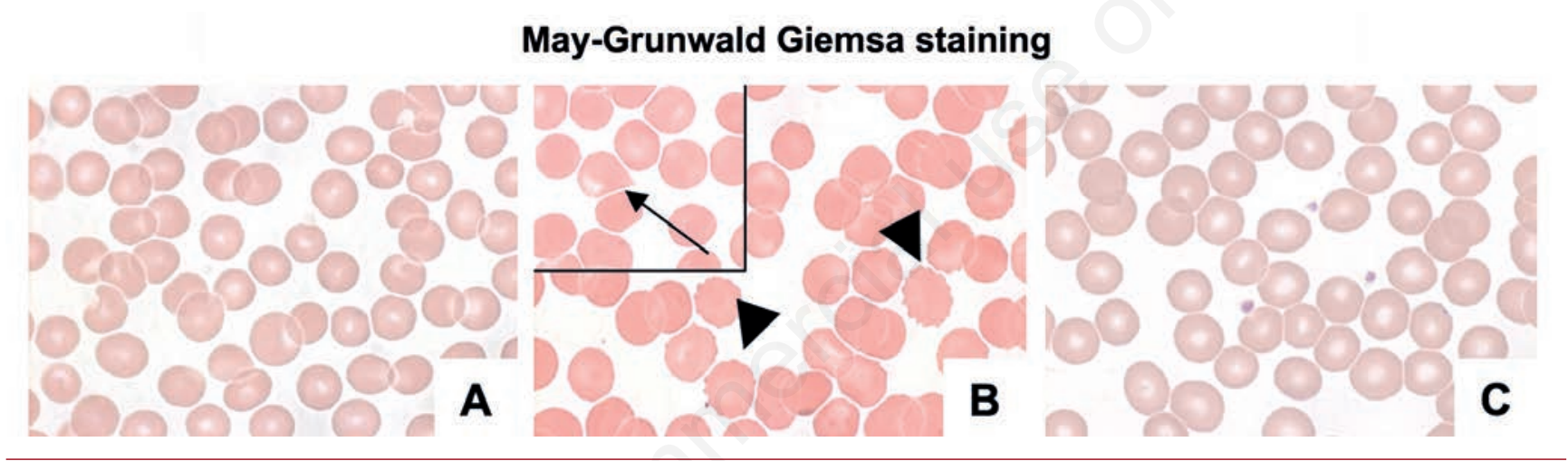

Figure 2. Photomicrographs stained by May Grunwald Giemsa showing RBCs from healthy (A), obese (B), and obese subjects after six weeks of omega-3 PUFA supplementation (C). Alterations are present in obese patients: echinocytes are marked with arrowheads; a dacrocyte is reported in a black square and it is indicated with an arrow. Scale bars: $20 \mu \mathrm{m}$.

\section{Morphological alterations in erythrocytes}

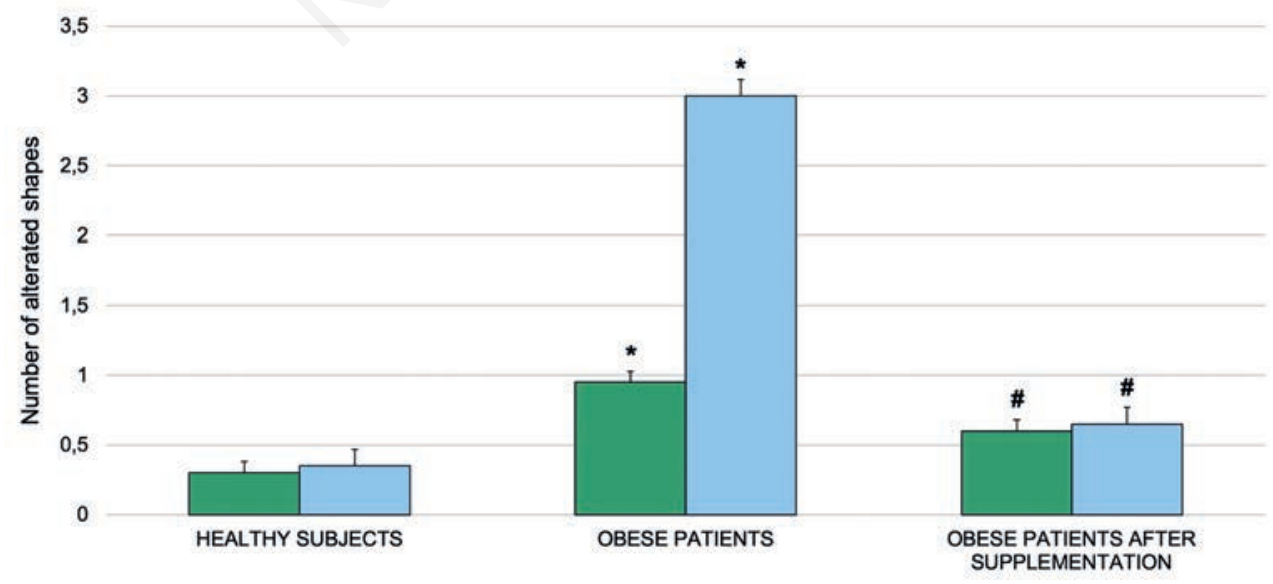

ロDACROCYTES

口ECHINOCYTES

Figure 3. Quantitative analyses showing the changes of RBC morphology in healthy and obese subjects before and after omega-3 PUFA supplementation. The results showed a significant reduction in the number of echinocytes and dacrocytes in obese subjects after six weeks of supplementation. Bars indicate mean $\pm \mathrm{SD}$. ${ }^{*} \mathrm{P} \leq 0.05$ vs healthy subjects; $\# \mathrm{P} \leq 0.05$ vs obese subjects. 
supplementation, the normal positivity was restored (Figure 4C).

The positivity's trend of CAT was similar to that observed for SOD-1 and its expression is evident in Figure 4 D-F.

\section{White blood cells}

SOD-1 expression was differently localized in the WBCs of healthy and obese subjects. Specifically, SOD-1 expression was weakly present in the cytoplasm of healthy subjects whereas its positivity was moderate in the nucleus and weak in the cytoplasm of obese patients (Figures 4A, B). After supplementation, the expression became more in line with that observed in healthy patients (Figure 4C). CAT expression showed the same findings as SOD-1 suggesting that these two enzymes have the same functions as promoters and regulators of oxidative stress (Figure $4 \mathrm{D}-\mathrm{F}$ ).

The semi-quantitative and quantitative observations are summarized in Table 2 and Figure 5 A,B, respectively.

\section{Role of IL-1 $\beta$ in the inflammatory state in WBCs}

\section{Red blood cells}

IL-1 $\beta$ expression was very weak in the RBC cytoplasm from healthy subjects (Figure 4G) and very weak or weak in the same cells from obese patients (Figure $4 \mathrm{H}$ ). The same pattern of healthy individuals has been observed in obese subjects after supplementation (Figure 4K).

\section{White blood cells}

As afterwards reported for iNOS, IL-1 $\beta$ expression was differently localized in the WBCs of healthy and obese subjects. In this case, in fact, the difference is more significant than that identified in RBCs. Specifically, IL-1 $\beta$ positivity was very weakly expressed in the WBC cytoplasm in healthy subjects (Figure 4G). These results became moderate in the obese patients (Figures $4 \mathrm{H}$ ).

\section{SOD-1}
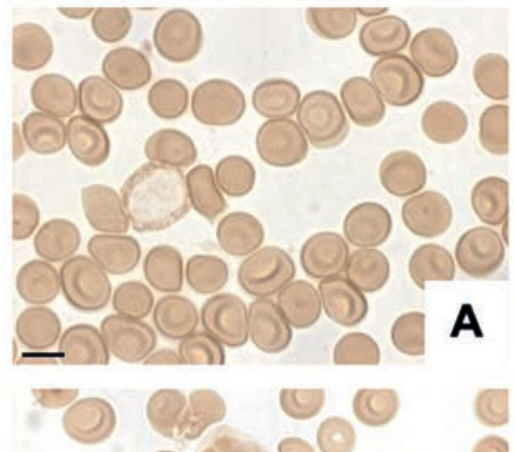

A
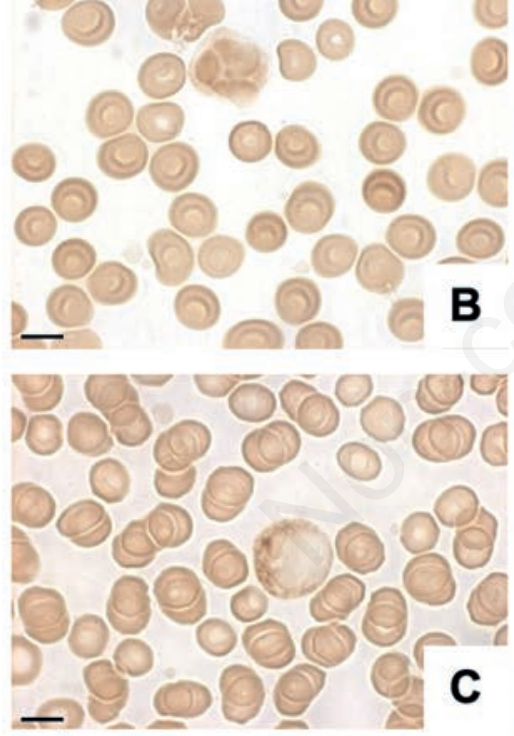

CAT

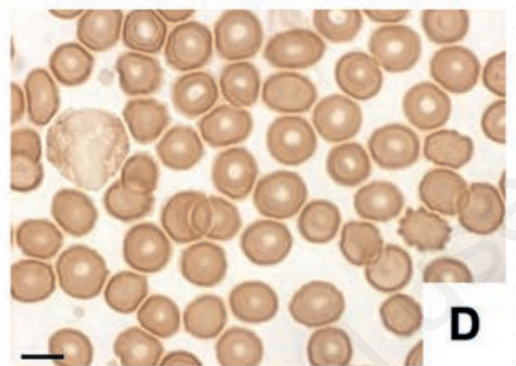

D
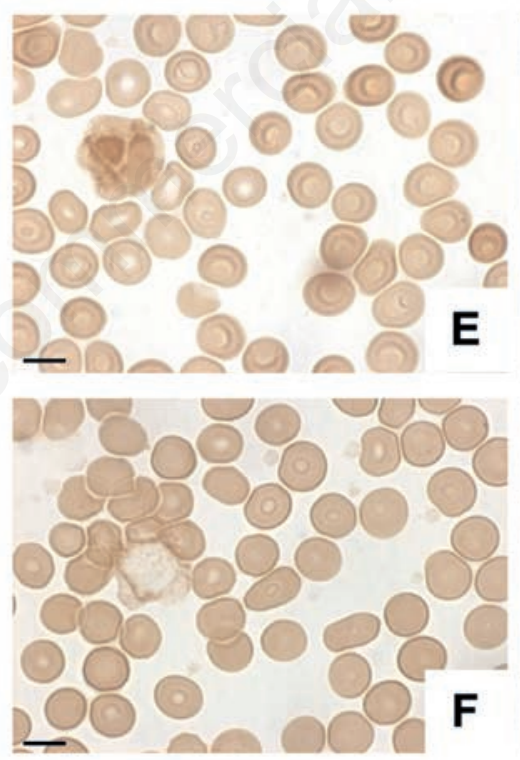

IL-1ß
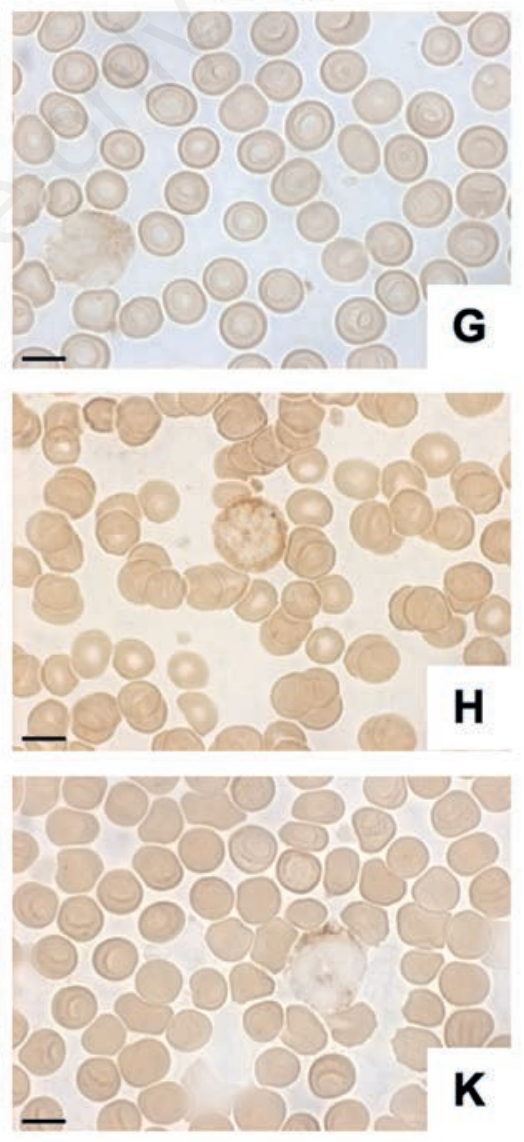

Figure 4. Photomicrographs showing SOD-1, CAT and IL-1 $\beta$ expression in RBCs and WBCs from healthy subjects (A,D,G) obese patients (B,E,H) and from obese patients after omega-3 PUFA supplementation (C,F,K). The results highlighted a different SOD-1, CAT and IL-1 $\beta$ expression in RBCs and WBCs in obesity and a positive effect of supplementation. Scale bars: $20 \mu \mathrm{m}$.

Table 2. Semi-quantitative analysis of SOD-1 and CAT in RBCs and WBCs from healthy and obese subjects before and after supplementation.

\begin{tabular}{|c|c|c|c|c|c|c|}
\hline & $\begin{array}{l}\text { Healthy } \\
\text { Subjects }\end{array}$ & $\begin{array}{c}\text { RBCs } \\
\text { Obese } \\
\text { subjects }\end{array}$ & $\begin{array}{l}\text { Obese subjects after } \\
\text { supplementation }\end{array}$ & $\begin{array}{l}\text { Healthy } \\
\text { Subjects }\end{array}$ & $\begin{array}{c}\text { WBCs } \\
\text { Obese } \\
\text { Subjects }\end{array}$ & $\begin{array}{l}\text { Obese subjects after } \\
\text { supplementation }\end{array}$ \\
\hline SOD-1 & ++ & + & ++ & + & $+/++$ & + \\
\hline CAT & ++ & + & ++ & + & $+/++$ & + \\
\hline
\end{tabular}


After supplementation, the expression returned similar to that observed in healthy patients (Figure 4K).

The semi-quantitative and quantitative observations are summarized in Table 3 and Figure 5C respectively.
Decrease of NF-kB expression in obesity and its upregulation with omega-3 PUFA supplementation

\section{Red blood cells}

RBCs were strongly NF-kB positive for healthy patients (Figure

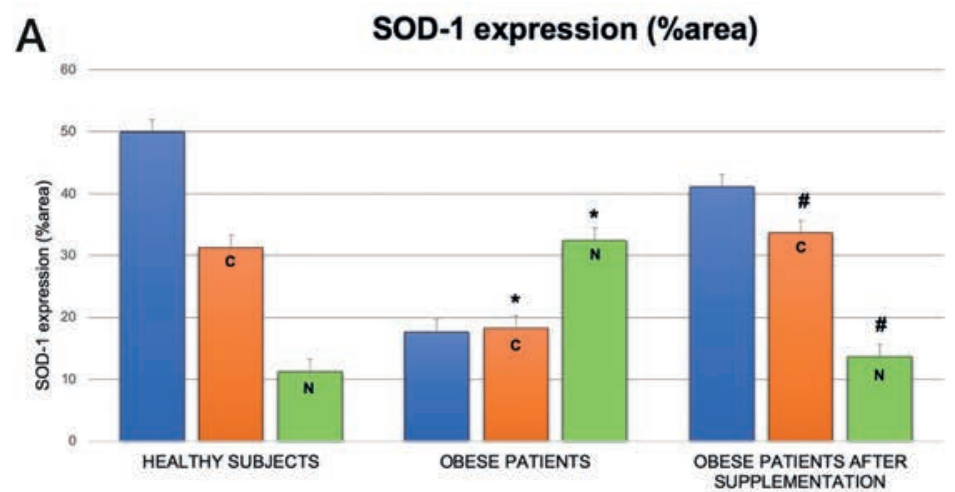

B

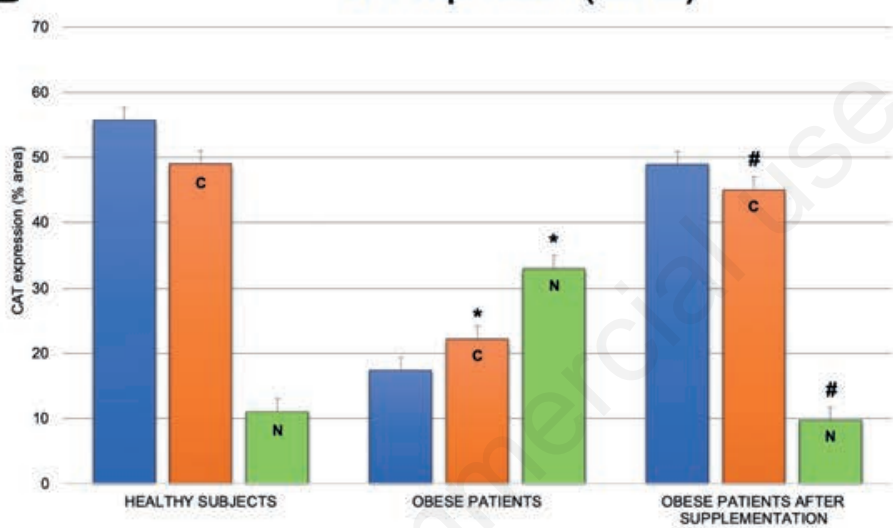

C IL-1 $\beta$ expression (\%area)

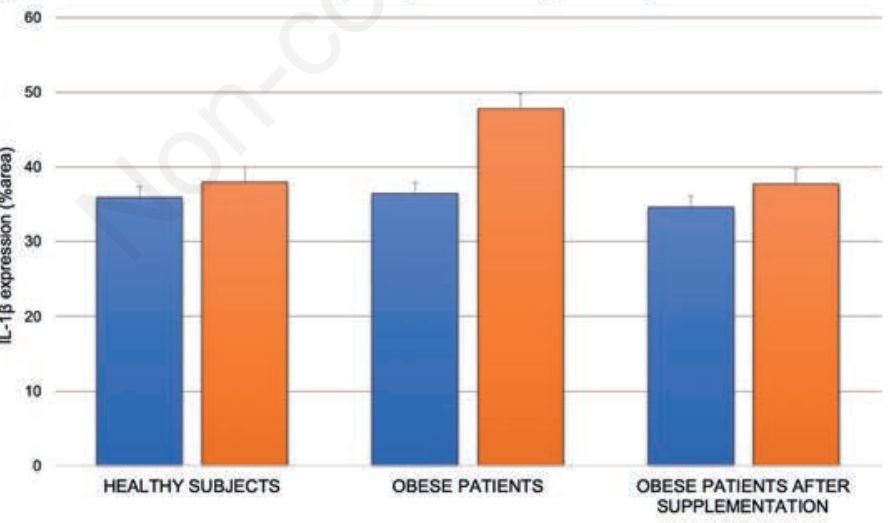

RBCs $\because$ WBC CYTOPLASM $\triangle$ WBC NUCLEUS $=R B C s$ -WBC CYTOPLASM WBC NUCLEUS

Figure 5. Histograms showing SOD-1 (A), CAT (B), and IL-1 $\beta(C)$, expression quantitatively reported as \%area, in RBCs and WBCs from healthy, obese and obese subjects before and after omega- 3 PUFA supplementation. Bars indicate mean \pm SD. ${ }^{*} \mathbf{P} \leq 0.05 v s$ healthy subjects, \# $\mathrm{P} \leq \mathbf{0 . 0 5}$ vs obese subjects; C, positivity expressed in the cytoplasm of WBCs; $\mathrm{N}$, positivity expressed in the cytoplasm of WBCs.

Table 3. Semi-quantitative analysis of IL-1 $\beta$ in RBCs and WBCs from healthy and obese subjects before and after supplementation.

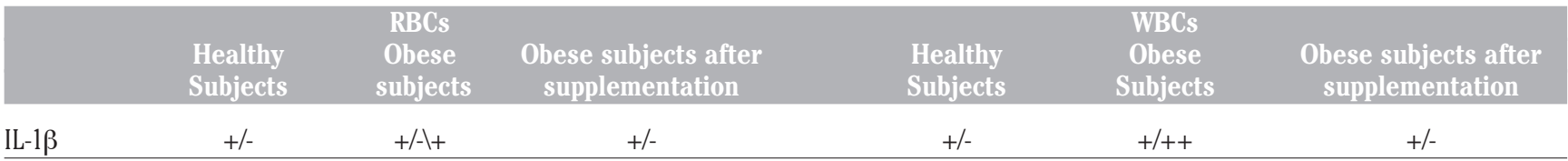


6A) and weakly positive for obese subjects (Figure 6B). Its expression was restored in obese patients after supplementation (Figure 6C).

With regard to eNOS, the positive trend was similar to that observed for NF-kB; its expression was moderate in $\mathrm{RBC}$ from healthy patients and very weak or weak in obese subjects (Figure 6 $\mathrm{D}, \mathrm{E})$. High positivity was reestablished after supplementation as shown in Figure 6F.

About iNOS expression, we observed very weak or weak staining in RBCs from healthy subjects and a negative or very weak positivity in obese patients (Figures $6 \mathrm{H}, \mathrm{G}$ ). After supplementation, the iNOS positivity was re-established (Figure 6K).

\section{White blood cells}

Notably, immunohistochemical analysis of NF-kB demonstrated that WBCs displayed a different positive trend than RBCs. NF-kB expression was weak in the WBC cytoplasm of healthy patients and moderate in obese subjects (Figures 6 A,B). In obese patients after supplementation its positivity was similar to that observed in healthy subjects and it was weak again in the cytoplasm (Figure 6C).

eNOS expression was very weak or weak in the WBC cytoplasm from healthy subjects (Figure 6D) and negative in the same cells from obese patients (Figure 6E). The same pattern of healthy individuals has been observed in obese subjects after supplementation (Figure 6F).

iNOS expression was negative in the WBCs of healthy people (Figure 6G). On the contrary, it was moderately expressed in the cytoplasm of obese patient WBCs (Figure 6H) and then disappeared in obese patients after supplementation (Figure 6K).

The semi-quantitative and quantitative observations are summarized in Table 4 and Figure 7, respectively.

\section{Discussion}

Evidence is provided herein of the non-canonical expression of NF-kB and NOS in the RBCs of healthy subjects and of their different positivity in obese subjects before and after six weeks of omega-3 PUFA supplementation. In addition, we compared the presence of oxidative and inflammatory markers in RBCs with those observed in WBCs, that here we considered as representative wellknown cellular model. In fact, WBC involvement in inflammation has been more thoroughly investigated although sometimes the results are conflicting, but, above all, the role and function of the proteins studied in nucleated cells have been, over the years, better defined than it has been in anucleated cells, as, for example, in red
NF-kB
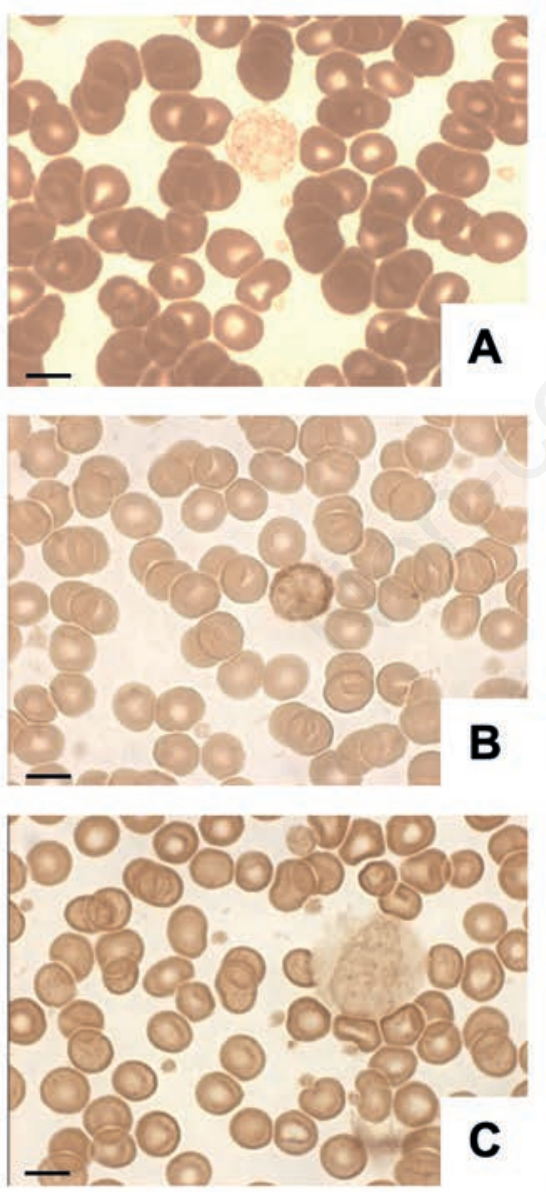

eNOS
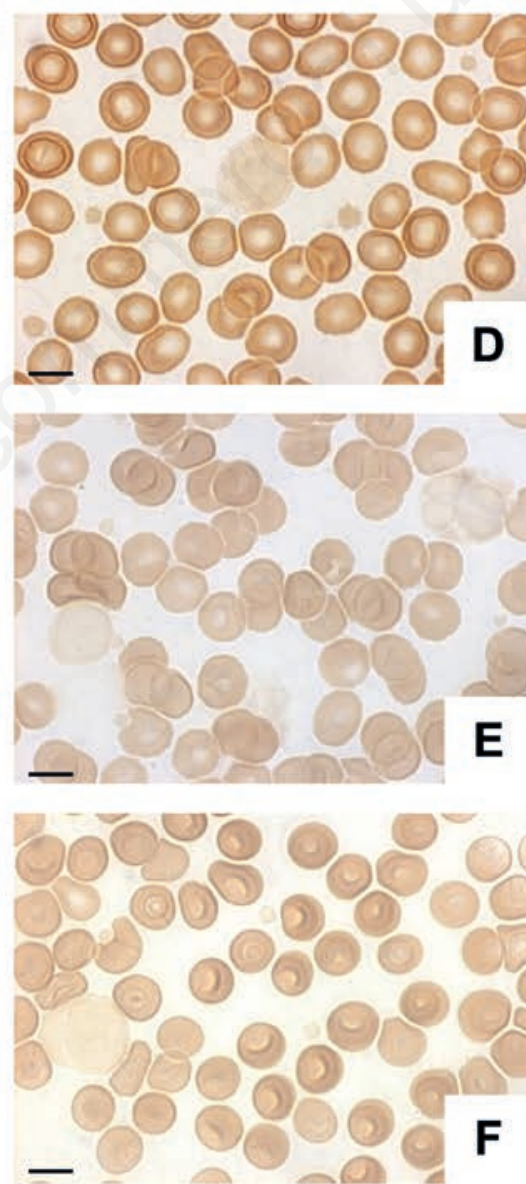
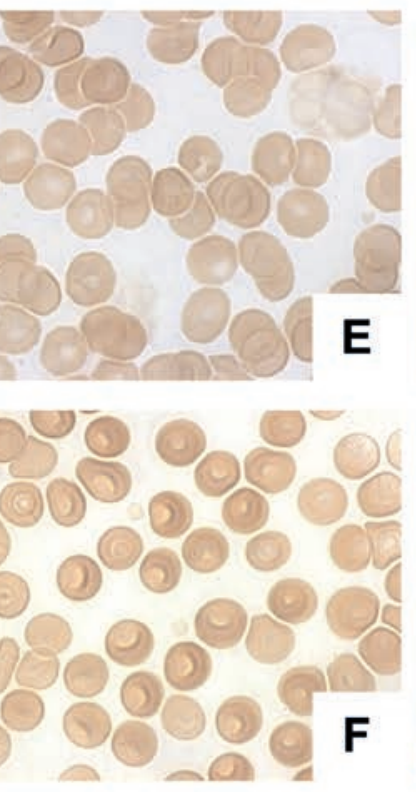

iNOS
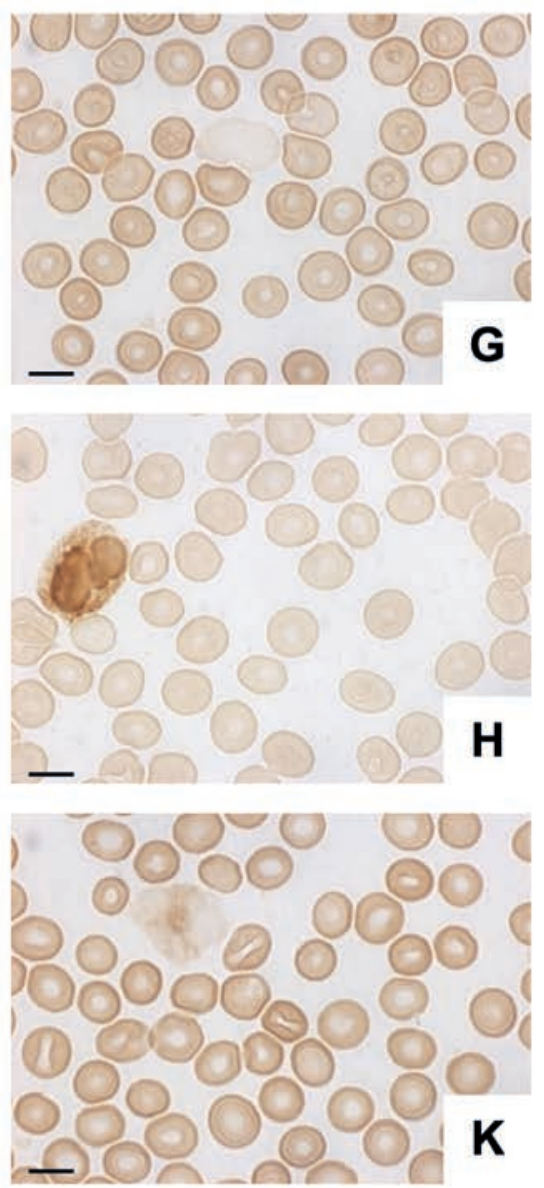

Figure 6. Photomicrographs showing NF-kB, eNOS and iNOS in RBCs and WBCs from healthy subjects (A,D,G) obese patients $(B, E, H)$ and from obese patients after omega-3 PUFA supplementation $(C, F, K)$. The results highlighted a different NF-kB, eNOS and iNOS expression in RBCs and WBCs in obesity and a positive effect of supplementation. Scale bars: $20 \mu \mathrm{m}$. 
A NFkB immunopositivity in RBCs and WBs (IOD)

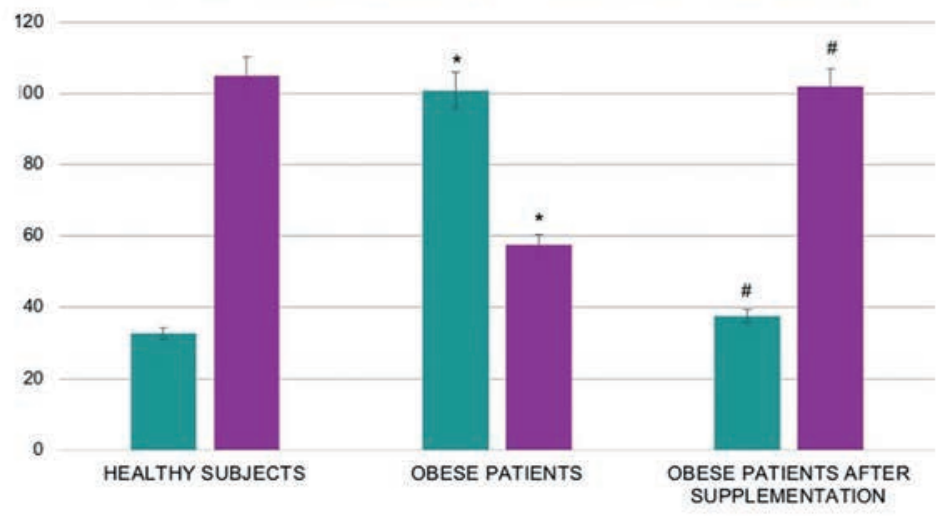

$=W B C=R B C$

\section{B eNOS immunopositivity in RBCs and WBs (IOD)}

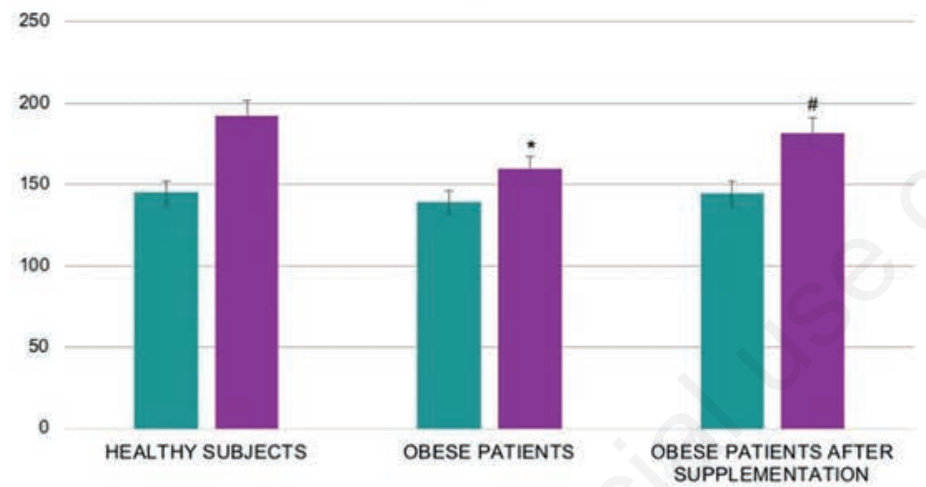

\section{C iNOS immunopositivity in RBCs and WBs (IOD)}

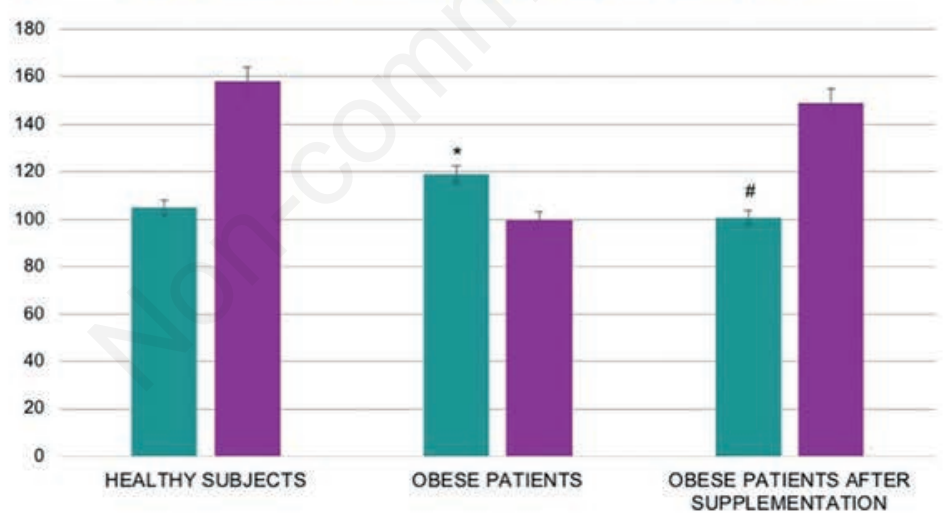

Figure 7. Histograms showing NF-kB (A), eNOS (B) and iNOS (C) expression quantitatively reported as IOD, in RBCs and WBCs from healthy, obese and obese subjects before and after omega-3 PUFA supplementation. The results showed the statistical change in the positivity of all three markers. Bars indicate mean \pm SD. ${ }^{*} \mathbf{P} \leq 0.05$ vs healthy subjects; $\# \mathrm{P} \leq 0.05$ vs obese subjects.

Table 4. Semi-quantitative analysis of NF-kB, eNOS and iNOS in RBCs and WBCs from healthy and obese subjects before and after supplementation.

\begin{tabular}{|c|c|c|c|c|c|c|}
\hline & $\begin{array}{l}\text { Healthy } \\
\text { Subjects }\end{array}$ & $\begin{array}{l}\text { RBCs } \\
\text { Obese } \\
\text { subjects }\end{array}$ & $\begin{array}{l}\text { Obese subjects after } \\
\text { supplementation }\end{array}$ & $\begin{array}{l}\text { Healthy } \\
\text { Subjects }\end{array}$ & $\begin{array}{c}\text { WBCs } \\
\text { Obese } \\
\text { Subjects }\end{array}$ & $\begin{array}{l}\text { Obese subjects after } \\
\text { supplementation }\end{array}$ \\
\hline NF-kB & +++ & + & $++\backslash+++$ & + & ++ & + \\
\hline eNOS & ++ & $+/-I_{+}$ & ++ & $+/ A_{+}$ & - & $+/ A_{+}$ \\
\hline iNOS & $+A_{+}$ & $-1+/-$ & $+/ A_{+}$ & - & ++ & - \\
\hline
\end{tabular}


blood cells. ${ }^{16,35,75,76}$ To our knowledge, there are few papers reporting the presence of NF-kB in anucleated cells. Spinelli et al. demonstrated the non-classical role of the NF-kB family in modulating platelet function; ${ }^{5}$ they demonstrated that its inhibition has deleterious effects on the platelet signaling pathways involved in shape change and spreading, modulation of clot retraction and thrombus stability under flow conditions. Furthermore, Ghashghaeinia et al. showed that RBCs do harbour NF-kB and IkB$\alpha$, its inhibitory protein that keeps it in the cytoplasm, even if they lose their nuclei. ${ }^{30}$ The authors suggested that this transcription factor is necessary for several functions other than the transcriptional one, necessary also for the RBCs, even if devoid of nucleus and transcriptional activity.

Intriguingly, we supported the differences in the expression of NF-kB in anucleated and nucleated cells. In fact, we showed that, in the RBCs and WBCs, NF-kB it is, respectively: i) strongly and weakly present in healthy volunteers; ii) weakly and moderately evident in obese subjects having the same pattern of iNOS expression. It is known that, in RBCs, NF-kB is important for their physiological functions and for maintaining their survival by delaying eryptosis as described by Ghashghaeinia et al., whereas in WBCs this protein is present as marker of inflammation, as well as iNOS and IL-1 $\beta .^{22,23,30,77}$ Moreover, obesity is associated with oxidative stress and inflammation, which trigger for eryptosis. ${ }^{78,79}$ In fact, we showed that NF-kB is moderately positive in WBCs from obese patients and this last result agrees with the findings demonstrating the complexity of the aetiology of obesity, a process that, overall, is markedly linked to inflammation and oxidative response. Notably, the characterization of this disease is difficult, and it includes the biological and environmental factors that are added to the consumption of a high-calorie diet combined with a reduction of physical activity. ${ }^{80}$ Inflammation has been implicated for better understanding the biological underpinnings of the risk of obesity and associated diseases. ${ }^{81}$ Moreover, we studied the inflammatory state of these cells considering the expression of IL$1 \beta \cdot{ }^{77}$ In addition, it is important to stress the presence of NF-kB compared to antioxidant enzymes both in RBCs and WBCs. In RBCs, NF-kB, SOD-1 and CAT have a similar positivity trend, since they are more expressed in good health compared to obesity. These findings could suggest that NF-kB can have the same role of fundamental antioxidant enzymes in RBCs. Recently, in fact, Kozakiewicz et al. demonstrated that lower activities of antioxidant enzymes in erythrocytes indicate an impairment of antioxidant defence in the aging organism. ${ }^{82}$ In WBCs, these proteins showed a similar positivity but they are differently localized in good health and obesity ${ }^{82}$. In obese subjects, NF-kB positivity was evident in the nucleus of WBCs while antioxidant enzymes were localized in the cytoplasm of these cells. As concerns nuclear-positivity expression of SOD-1 and CAT in obese patients, the findings indicate that these proteins move from the cytoplasm to the nucleus during the inflammatory response, probably in order to regulate the expression of a large set of oxidative response genes that are known

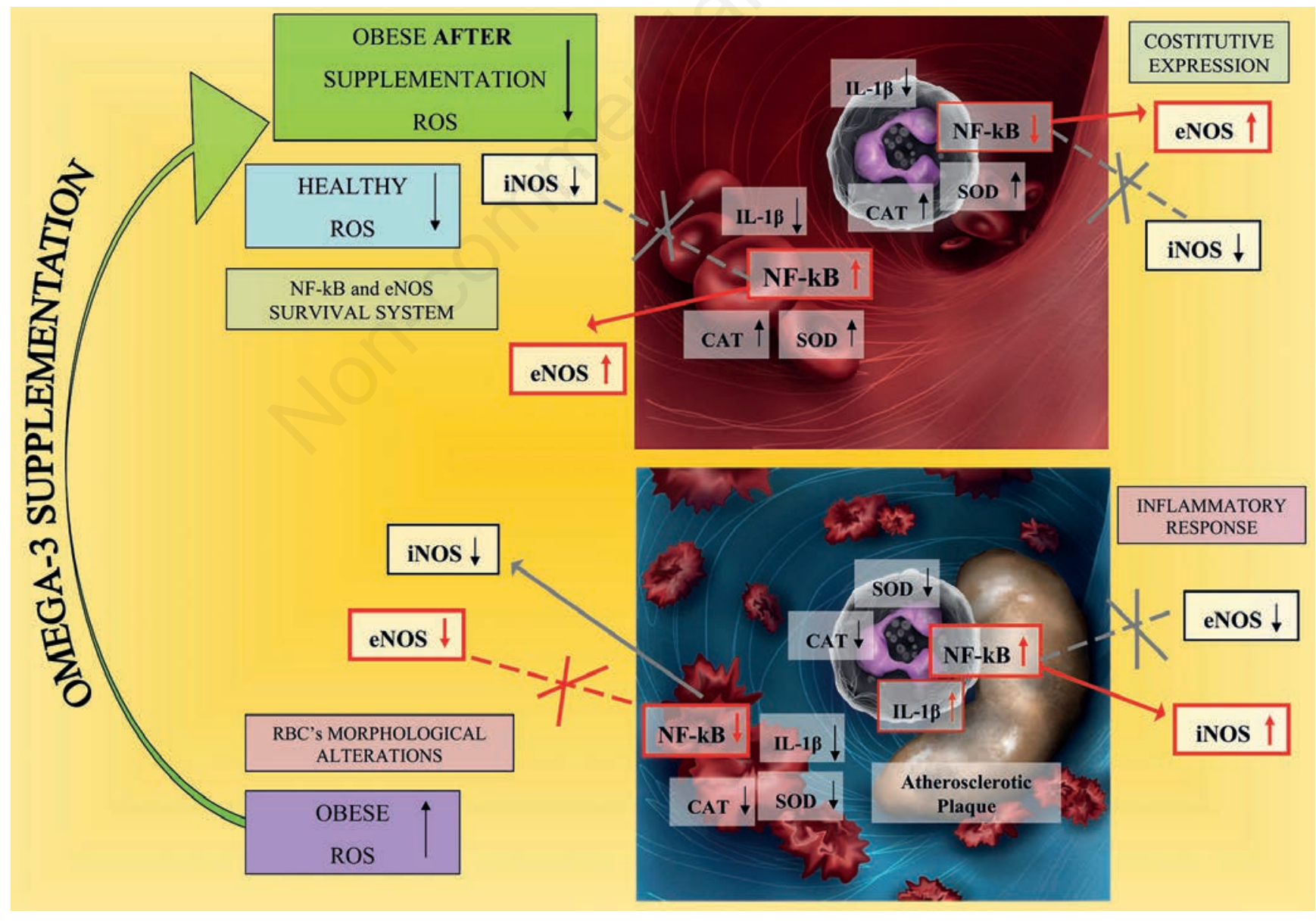

Figure 8. Schematic representation showing the results obtained during the study. 
to provide resistance to oxidative stress, DNA damage repair and relief of replication stress. ${ }^{83,84}$ With regard to NF-kB its presence in the cytoplasm of WBC from obese patients could indicate that when, it is activated, it enters the nucleus to induce transcription of a myriad of genes that mediate many cellular processes such as immunity, inflammation, proliferation, apoptosis, and cellular senescence as demonstrated by Muriach et al. ${ }^{85}$ Thus, we can suggest that NF-kB could have a dual role being on one side prolifespan, in RBCs, and on the other side, in WBCs and in nucleated cells, stimulating pro-inflammatory processes, modifying its activity depending on the different cells in which it is examined.

Another interesting finding is that eNOS has the same positivity pattern as NF-kB in the RBCs of healthy and obese subjects. It is well-known that the most common route of NO production is through the action of NOS, and while iNOS produces high amounts of NO in multiple cell types in response to inflammatory stimuli as reported above, eNOS generates low quantities of NO and its activity occurs in physiological conditions..$^{22,86-89} \mathrm{NO}$ bioavailability decreases in metabolic syndromes both in human and animal studies..$^{90,91}$ This is due to the decrease in expression of eNOS activity that could be attributed to insulin resistance and mediated by NF-kB. ${ }^{71}$ So, our results confirmed these findings by showing that NF-kB could be defined also as an enzyme that enables the eNOS expression and, probably, its activity in the RBCs of healthy subjects, stimulate, instead, higher work by iNOS in the WBCs of obese patients. In fact, iNOS positivity increased in the WBCs of obese patients, while eNOS expression decreased in the RBCs and WBCs of obese patients.

The positivity pattern described for iNOS is the same that we have also depicted for IL-1 $\beta$ : these results allowed to suppose the existence of a link between obesity, oxidative stress, inflammatory response, IL-1 $\beta$ and also iNOS in WBCs. These results agree with those depicted from different authors demonstrating that RBCs obtained from obese participants show dynamic stretching behaviour in extensional flows. These metabolic abnormalities include traits that characterize metabolic syndrome and insulin resistance and chronic inflammation..$^{91,92}$

Last but not least are the results showing that omega-3 PUFA administered to obese patients for three and six weeks partially restore the positivity of the proteins examined over time.

We decided to start this supplementation following previous results showing a good impact of RBCs morphology after PUFA administration. RBC deformability and platelets aggregation are two features of main importance considering the development of cardiovascular diseases. ${ }^{93}$ Moreover, RBC shape is strictly linked to the oxidative stress of the cells and to the presence of different quantity of NO. ${ }^{11}$

Starting from this background, we considered studies that confirm, first of all the presence of EPA and DHA in RBC membrane, secondly, the possibility of modulating their composition after PUFA supplementation. Cao and colleagues showed that also a two-week-long supplementation could modify the $\mathrm{RBC}$ membrane composition, ${ }^{93}$ acting on platelets aggregability, too. ${ }^{94} \mathrm{We}$ also look at RBC shape, through May-Grunwald and Giemsa staining stained smears, in order to look for any significative changes. We suppose that six weeks of supplementation is no longer enough to affect the lifecycle of these cells, but it could lead some morphological modifications useful in order to maintain $\mathrm{RBC}$ functionality. In addition, the positivity of proteins and of the aforementioned inflammatory markers is statistically restored and similar to that observed in healthy volunteers after six weeks of supplementation. So, we can suggest that omega-3 PUFA supplementation is able to modulate the omega-6/omega-3 ratio in blood cells markedly by contributing significantly to the expression and synthesis of a variety of proteins, such as those we studied. In this way this supplementation is able to increase antioxidant enzymes and NF-kB that, in turn, modulates NOS. Anyway, beyond the changes obtained in the expression of the markers considered above, it is important to try to clarify the role of supplementation in these cells: other studies using different therapeutic approach of omega-3 PUFA supplementation involve patients for a variable period of time, from four weeks to more..$^{72}$

Our results have shown that six weeks of supplementation is enough to induce a change in the expression of cytoplasmic proteins, defining also some alterations in the morphologies of WBCs. Given the physiological half-life of RBCs, we could suggest that the beneficial effect of supplementation is not related to a change in the survival of these cells, nevertheless, the effect that this brief supplementation already seems to have on the morphology of RBCs and on their protein complement, even if not affecting lifecycle, could be an interesting starting point for evaluating a possible therapeutic use of this supplementation. In this context, in agreement with Brigandi et al., we could suggest that RBC phospholipid fatty acid evaluation is an important biomarker for fatty acid status in tissues and organs. ${ }^{95}$ It is also worth mentioning that cell membranes are a determinant tool for controlling the membrane properties and functions during diseases and aging. ${ }^{96,97}$ Moreover, our data could indicate that the changes in fatty acids on the RBC membranes influence also the morphology of the same cells.

These considerations are fundamental to better clarify the purpose of our work and the reasons that led us to conduct this clinical trial. Although these data have to be better investigated, they have allowed us to confirm, first of all, the existence of a correlation between oxidative stress and the expression of specific proteins. Secondly, it has been possible to confirm that the supplementation with omega-3 PUFA is sufficient to modify the expression of the proteins previously analysed: the mechanism of action is not yet clear, but future trials will enable major advances on treatment researches on omega-6/omega-3 ratio and other clinical implications.

Our conclusion, summarized in Figure 8, supports the noncanonical and positive role of NF-kB in RBCs and its inflammatory functions in WBCs respectively in good health and obesity. In addition, we emphasize the fact that a high omega-6/omega-3 PUFA ratio, as is found in today's Western diets, promotes the pathogenesis of many diseases, including obesity, whereas increased levels of omega-3 PUFA (a lower omega-6/omega-3 ratio), exert protective effects.

\section{Acknowledgments}

The Authors would like to thank Miss Greta Magaraggia, degree in design and publication, for her contribute in drafting the Figure 8. The English language was revised by Studio Moretto, a Professional English Group in Brescia (Italy).

\section{References}

1. Nemkov T, Reisz JA, Xia Y, Zimring JC, D'Alessandro A. Red blood cells as an organ? How deep omics characterization of the most abundant cell in the human body highlights other systemic metabolic functions beyond oxygen transport. Expert Rev Proteomics 2018;15:855-64.

2. Cui L, Takada H, Takimoto T, Fujiyoshi J, Ishimura M, Hara T. Immunoregulatory function of neonatal nucleated red blood cells in humans. Immunobiology 2016;221:853-61. 
3. Pitanga TN, Oliveira RR, Zanette DL, Guarda CC, Santiago RP, Santana SS, et al. Sickle red cells as danger signals on proinflammatory gene expression, leukotriene B4 and interleukin-1 beta production in peripheral blood mononuclear cell. Cytokine 2016;83:75-84.

4. Erdei J, Tóth A, Balogh E, Nyakundi BB, Bányai E, Ryffel B, et al. Induction of NLRP3 Inflammasome Activation by Heme in Human Endothelial Cells. Oxid Med Cell Longev 2018;2018:1-14.

5. Yin Y, Ye S, Wang H, Li B, Wang A, Yan W, et al. Red blood cell distribution width and the risk of being in poor glycemic control among patients with established type 2 diabetes. Ther Clin Risk Manag 2018;14:265-73.

6. Kuhn V, Diederich L, Keller TCS 4th, Kramer CM, Lückstädt W, Panknin C, et al. Red blood cell function and dysfunction: Redox regulation, nitric oxide metabolism, anemia. Antioxid Redox Signal 2017;26:718-42.

7. Higareda-Almaraz JC, Enríquez-Gasca Mdel R, HernándezOrtiz M, Resendis-Antonio O, Encarnación-Guevara S. Proteomic patterns of cervical cancer cell lines, a network perspective. BMC Syst Biol 2011;5:96.

8. Spinelli SL, Casey AE, Pollock SJ, Gertz JM, McMillan DH, Narasipura SD, et al. Platelets and megakaryocytes contain functional nuclear factor-kappaB. Arterioscler Thromb Vasc Biol 2010;30:591-8.

9. Cortese-Krott MM, Kelm M. Endothelial nitric oxide synthase in red blood cells: key to a new erythrocrine function? Redox Biol 2014;2:251-8.

10. Porro B, Eligini S, Squellerio I, Tremoli E, Cavalca V. The red blood cell: a new key player in cardiovascular homoeostasis? Focus on the nitric oxide pathway. Biochem Soc Trans 2014;42:996-1000.

11. Diederich L, Suvorava T, Sansone R, Keller TCS 4th, Barbarino F, Sutton TR, et al. On the effects of reactive oxygen species and nitric oxide on red blood cell deformability. Front Physiol 2018;9:332.

12. Lucas PC, McAllister-Lucas LM, Nunez G. NF-kappaB signaling in lymphocytes: a new cast of characters. J Cell Sci 2004; $117: 31-9$.

13. Nennig SE, Schank JR. The role of NFkB in drug addiction: Beyond inflammation. Alcohol Alcohol 2017;52:172-9.

14. Aktan F. iNOS-mediated nitric oxide production and its regulation. Life Sci 2004;75:639-53.

15. Gilmore TD. Introduction to NF-kappaB: players, pathways, perspectives. Oncogene 2006;25:6680-4.

16. Vannini F, Kashfi K, Nath N. The dual role of iNOS in cancer. Redox Biol 2015;6:334-43.

17. Lind M, Hayes A, Caprnda M, Petrovic D, Rodrigo Lm, Kruzliak P, et al. Inducible nitric oxide synthase: Good or bad? Biomed Pharmacother 2017;93:370-5.

18. Bent R, Moll L, Grabbe S, Bros M. Interleukin-1 Beta-A Friend or Foe in Malignancies? Int J Mol Sci 2018;19:1-34.

19. Piccarducci R, Pietrobono D, Pellegrini C, Daniele S, Fornai M, Antonioli L, et al. High levels of $\beta$-amyloid, tau, and phospho-tau in red blood cells as biomarkers of neuropathology in senescence-accelerated mouse. Oxid Med Cell Longev 2019;2019:1-16.

20. Mungrue N, Gros R, You X, Pirani A, Azad A, Csont T, et al. Cardiomyocyte overexpression of iNOS in mice results in peroxynutrite generation, heart block, and sudden death. J. Clin. Invest 2002;109:735-43.

21. Xue Q, Yan Y, Zhang R, Xiong H. Regulation of iNOS on immune cells and its role in diseases. Int $\mathrm{J}$ Mol Sci 2018;19:3805.

22. Kone BC, Kuncewicz T, Zhang W, Yu ZY. Protein interactions with nitric oxide synthases: controlling the right time, the right place, and the right amount of nitric oxide. Am J Physiol Renal Physiol 2003;285:178-90.

23. Kleinert H, Pautz A, Linker K, Schwarz PM. Regulation of the expression of inducible nitric oxide synthase. Eur J Pharmacol 2004;500:255-66.

24. Forbes SP, Alferiev IS, Chorny M, Adamo RF, Levy RJ, Fishbein I. Modulation of NO and ROS production by AdiNOS transduced vascular cells through supplementation with L-Arg and BH4: Implications for gene therapy of restenosis. Atherosclerosis 2013;230:23-32.

25. Kim F, Tysseling KA, Rice J, Pham M, Haji L, Gallis BM, et al. Free fatty acid impairment of nitric oxide production in endothelial cells is mediated by IKKbeta. Arterioscler Thromb Vasc Biol 2005;25:989-94.

26. Kim F, Pham M, Luttrell I, Bannerman DD, Tupper J, Thaler J, et al. Toll-like receptor-4 mediates vascular inflammation and insulin resistance in diet-induced obesity. Circ Res 2007;100:1589-96.

27. Suganami T, Tanimoto-Koyama K, Nishida J, Itoh M, Yuan X, Mizuarai S, et al. Role of the Toll-like receptor 4/NF-kappaB pathway in saturated fatty acid-induced inflammatory changes in the interaction between adipocytes and macrophages. Arterioscler Thromb Vasc Biol 2007;27:84-91.

28. Gu Y, Hu K, Huang Y, Zhang Q, Liu L, Meng G, et al. White blood cells count as an indicator to identify whether obesity leads to increased risk of type 2 diabetes. Diabetes Res Clin Pract 2018;141:140-7.

29. Ghashghaeinia M, Toulany M, Saki M, Rodemann HP, Mrowietz U, Lang F, et al. Potential roles of the NFאB and glutathione pathways in mature human erythrocytes. Cell Mol Biol Lett 2012;17:11-20.

30. Ghashghaeinia M, Toulany M, Saki M, Bobbala D, Fehrenbacher B, Rupec R, et al. The NFKB pathway inhibitors Bay 11-7082 and parthenolide induce programmed cell death in anucleated erythrocytes. Cell Physiol Biochem 2011;27:45-54.

31. Martins MA, Moss MB, Mendes IK, Águila MB, Mandarimde-Lacerda CA, Brunini TM, et al. Role of dietary fish oil on nitric oxide synthase activity and oxidative status in mice red blood cells. Food Funct 2014;5:3208-15.

32. Nagarajan S, Raj RK, Saravanakumar V, Balaguru UM, Behera $\mathrm{J}$, Rajendran VK, et al. Mechanical perturbations trigger endothelial nitric oxide synthase activity in human red blood cells. Sci Rep 2016;6:26935.

33. Martins MA, Catta-Preta M, Mandarim-de-Lacerda CA, Aguila MB, Brunini TC, Mendes-Ribeiro AC. High fat diets modulate nitric oxide biosynthesis and antioxidant defence in red blood cells from C57BL/6 mice. Arch Biochem Biophys 2010;499:56-61.

34. Lohman AW, Weaver JL, Billaud M, Sandilos JK, Griffiths R, Straub AC, et al. S-nitrosylation inhibits pannexin 1 channel function. J Biol Chem 2012;287:39602-12.

35. Guo Y, Sanganalmath SK, Wu W, Zhu X, Huang Y, Tan W, et al. Identification of inducible nitric oxide synthase in peripheral blood cells as a mediator of myocardial ischemia/reperfusion injury. Basic Res Cardiol 2012;107:1-14.

36. Naseem KM, Riba R. Unresolved roles of platelet nitric oxide synthase. J Thromb Haemost 2008;6:10-9.

37. Gambaryan S, Kobsar A, Hartmann S, Birschmann I, Kuhlencordt PJ, Müller-Esterl W, et al. NO-synthase-/NOindependent regulation of human and murine platelet soluble guanylyl cyclase activity. J Thromb Haemost 2008;6:1376-84.

38. Emami Z, Mesbah Namin A, Kojuri J, Mashayekhi Jalali F, Rasti M. Expression and activity of platelet endothelial nitric oxide synthase are decreased in patients with coronary thrombosis and stenosis. Avicenna J Med Biotechnol 
2019;11:88-93.

39. Fernández-Sánchez A, Madrigal-Santillán E, Bautista M, Esquivel-Soto J, Morales-González A, Esquivel-Chirino C, et al. Inflammation, oxidative stress, and obesity. Int J Mol Sci 2011;12:3117-32.

40. Thota RN, Ferguson JJA, Abbott KA, Dias CB, Garg ML. Science behind the cardio-metabolic benefits of omega-3 polyunsaturated fatty acids: biochemical effects vs. clinical outcomes. Food Funct 2018;9:3576-96.

41. Yates CM, Calder PC, Ed Rainger G. Pharmacology and therapeutics of omega-3 polyunsaturated fatty acids in chronic inflammatory disease. Pharmacol Ther 2014;141:272-82.

42. Rocha DM, Bressan J, Hermsdorff HH. The role of dietary fatty acid intake in inflammatory gene expression: a critical review. Sao Paulo Med J 2017;135:157-68.

43. Baker EJ, Yusof MH, Yaqoob P, Miles EA, Calder PC. Omega3 fatty acids and leukocyte-endothelium adhesion: Novel anti-atherosclerotic actions. Mol Aspects Med 2018;64:169-81.

44. Mansara P, Ketkar M, Deshpande R, Chaudhary A, Shinde K, Kaul-Ghanekar R. Improved antioxidant status by omega-3 fatty acid supplementation in breast cancer patients undergoing chemotherapy: a case series. J Med Case Rep 2015;9:148.

45. Allam-Ndoul B, Guénard F, Barbier O, Vohl MC. Effect of n-3 fatty acids on the expression of inflammatory genes in THP-1 macrophages. Lipids Health Dis 2016;15:69.

46. Di Nunzio M, Valli V, Bordoni A. PUFA and oxidative stress. Differential modulation of the cell response by DHA. Int J Food Sci Nutr 2016;67:834-43.

47. Ristic Medić D, Ristić V, Arsić A, Postic M, Ristic G, Blazencić Mladenović V, et al. Effects of soybean D-LeciVita product on se- rum lipids and fatty acid composition in type 2 diabetic patients with hyperlipidemia. Nutr Metab Cardiovasc Dis 2006;16:395-404.

48. Choi HN, Yim JE. Effects of erythrocyte membrane polyunsaturated fatty acids in overweight, obese, and morbidly obese Korean women. J Cancer Prev 2017;22:182-8.

49. Kim OY, Lee SM, An WS. Impact of blood or erythrocyte membrane fatty acids for disease risk prediction: focusing on cardiovascular disease and chronic kidney disease. Nutrients 2017; 10:1454.

50. Papandreou C, Sala-Vila A, Galié S, Muralidharan J, Estruch R, Fitó M, et al. Association between fatty acids of blood cell membranes and incidence of coronary heart disease. Arterioscler Thromb Vasc Biol 2019;39:819-25.

51. Simopoulos AP. An increase in the omega-6/omega-3 fatty acid ratio increases the risk for obesity. Nutrients 2016;8:128.

52. Kelly T, Yang W, Chen CS, Reynolds K, He J. Global burden of obesity in 2005 and projections to 2030. Int J Obes 2008;32:1431-7.

53. Brunner S, Schmid D, Hüttinger K, Much D, Brüderl M, Sedlmeier EM, et al. Effect of reducing the n-6/n-3 fatty acid ratio on the maternal and fetal leptin axis in relation to infant body composition. Obesity 2014;22:217-24.

54. Dolin CD, Kominiarek MA. Pregnancy in women with obesity. Obstet Gynecol Clin North Am.2018;45:217-32.

55. Laudisio D, Muscogiuri G, Barrea L, Savastano S, Colao A. Obesity and breast cancer in premenopausal women: Current evidence and future perspectives. Eur J Obstet Gynecol Reprod Biol 2018;230:217-21

56. Kitson SJ, Lindsay J, Sivalingam VN, Rutter MK, Crosbie EJ. High prevalence of metabolic syndrome in women newly diagnosed with endometrial cancer. Gynecol Oncol Rep 2018;26:109-10.

57. Pickett-Blakely O, Uwakwe L, Rashid F. Obesity in women: The clinical impact on gastrointestinal and reproductive health and disease management. Gastroenterol Clin North Am 2016;45:317-31.

58. Williams EP, Mesidor M, Winters K, Dubbert PM, Wyatt SB. Overweight and obesity: Prevalence, consequences, and causes of a growing public health problem. Curr Obes Rep. 2015;4:363-70.

59. Albracht-Schulte K, Kalupahana NS, Ramalingam L, Wang S, Rahman SM, Robert-McComb J, et al. Omega-3 fatty acids in obesity and metabolic syndrome: a mechanistic update. J Nutr Biochem 2018;58:1-16.

60. Vessby B. Dietary fat, fatty acid composition in plasma and the metabolic syndrome. Curr Opin Lipidol 2003;14:15-9.

61. Burdge GC, Wootton SA. Conversion of alpha-linolenic acid to palmitic, palmitoleic, stearic and oleic acids in men and women. Prostaglandins Leukot Essent Fatty Acids 2003;69:283-90.

62. Lavie CJ, Milani RV, Mehra MR, Ventura HO. Omega-3 polyunsaturated fatty acids and cardiovascular diseases. J Am Coll Cardiol 2009;54:585-94.

63. Bimbo AP. Sources of omega-3 fatty acids. Jacobsen Ch, Nielsen NS, Horn AF, Sørensen AD, editors. Woodhead Publishing Limited (Cambridge); 2013.

64. Vuksan V, Jenkins AL, Brissette C, Choleva L, Jovanovski E, Gibbs AL, et al. Salba-chia (Salvia hispanica L.) in the treatment of overweight and obese patients with type 2 diabetes: A doubleblind randomized controlled trial. Nutr Metab Cardiovasc Dis 2017:27:138-46.

65. de Falco B, Amato M, Lanzotti V. Chia seeds products: an overview. Phytochem Rev 2017;16:745-60.

66. Thorpe SJ, Thein SL, Sampietro M, Craig JE, Mahon B, Huehns ER. Immunochemical estimation of haemoglobin types in red blood cells by FACS analysis. Br J Haematol 1994;87:125-32.

67. Paździor-Czapula K, Gesek M, Rotkiewicz T, Kluciński W, Kołodziejska J, Kleczkowski M, et al. Immunohistochemical evaluation of superoxide dismutase $(\mathrm{Cu} / \mathrm{Zn} \quad \mathrm{SOD})$ concentrations in erythrocytes of dairy cattle and farm-raised deer by a computer-assisted analysis of microscopic images. Pol J Vet Sci 2014;17:275-9.

68. Esmaeilnejad B, Tavassoli M, Samiei A, Hajipour N, ImaniBaran A, Farhang-Pajuh F. Evaluation of oxidative stress and antioxidant status, serum trace mineral levels and cholinesterases activity in cattle infected with Anaplasma marginale. Microb Pathog 2018;123:402-9.

69. Bandesh K, Jha P, Giri AK, Marwaha RK, INDICO, Scaria V, Tandon N, et al. Normative range of blood biochemical parameters in urban Indian school-going adolescents. PLoS One 2019;14:1-15.

70. Jalali SM, Bahrami S, Rasooli A, Hasanvand S. Evaluation of oxidant/antioxidant status, trace mineral levels, and erythrocyte osmotic fragility in goats naturally infected with Anaplasma ovis. Trop Anim Health Prod 2016;48:1175-81.

71. Fedchenko N, Reifenrath J. Different approaches for interpretation and reporting of immunohistochemistry analysis results in the bone tissue - a review. Diagn Pathol 2014;9:221.

72. Reeve AK, Park TK, Jaros E, Campbell GR, Lax NZ, Hepplewhite PD, et al. Relationship between mitochondria and $\alpha$-synuclein: a study of single substantia nigra neurons. Arch Neurol 2012;69:385-93.

73. Seljeflot I, Arnesen H, Brude IR, Nenseter MS, Drevon CA, Hjermann I. Effects of omega-3 fatty acids and/or antioxidants on endothelial cell markers. Eur J Clin Invest 1998;28:629-35.

74. Ford J. Red blood cell morphology. Int J Lab Hematol 2013;35:351-7.

75. Wink DA, Mitchell JB. Chemical biology of nitric oxide: Insights into regulatory, cytotoxic, and cytoprotective mechanisms of nitric oxide. Free Radic Biol Med 1998;25:434-56. 
76. Lechner M, Lirk P, Rieder J. Inducible nitric oxide synthase (iNOS) in tumor biology: the two sides of the same coin. Semin Cancer Biol 2005; 15:277-89.

77. Gabay C, Lamacchia C, Palmer G. IL-1 pathways in inflammation and human diseases. Nat Rev Rheumatol 2010;6:232-41.

78. Wiewiora M, Piecuch J, Sedek L, Mazur B, Sosada K. The effects of obesity on CD47 expression in erythrocytes. Cytometry B Clin Cytom 2017;92:485-91.

79. Wodarczyk M, Nowicka G. Obesity, DNA damage, and development of obesity-related diseases. Int J Mol Sci 2019;20:1146.

80. Seong J, Kang JY, Sun JS, Kim KW. Hypothalamic inflammation and obesity: a mechanistic review. Arch Pharm Res 2019;42:383-92.

81. Cox AJ, West NP, Cripps AW. Obesity, inflammation, and the gut microbiota. Lancet Diabetes Endocrinol 2015;3:207-15.

82. Kozakiewicz M, Kornatowski M, Krzywińska O, KędzioraKornatowska K. Changes in the blood antioxidant defense of advanced age people. Clin Interv Aging 2019;14:763-71.

83. Tsang CK, Liu Y, Thomas J, Zhang Y. Zheng XF. Superoxide dismutase 1 acts as a nuclear transcription factor to regulate oxidative stress resistance. Nat Commun 2014;5:3446.

84. Amaral JH, Rizzi ES, Alves-Lopes R, Pinheiro LC, Tostes RC, Tanus-Santos JE. Antioxidant and antihypertensive responses to oral nitrite involves activation of the Nrf2 pathway. Free Radic Biol Med 2019;141:261-8.

85. Muriach M, Flores-Bellver M, Romero FJ, Barcia JM. Diabetes and the brain: oxidative stress, inflammation, and autophagy. Oxid Med Cell Longev 2014;2014:44.

86. Alderton WK, Cooper CE, Knowles RG. Nitric oxide synthases: structure, function and inhibition. Biochem J 2001;357:593-615.

87. Hill BG, Dranka BP, Bailey SM, Lancaster JR Jr, Darley-Usmar VM. What part of NO don't you understand? Some answers to the cardinal questions in nitric oxide biology. J Biol Chem 2010;285:19699-704.

88. Sansbury BE, Hill BG. Regulation of obesity and insulin resistance by nitric oxide. Free Radic Biol Med 2014;73:383-99.

89. Balligand JL, Feron O, Dessy C. eNOS activation by physical forces: from short-term regulation of contraction to chronic remodeling of cardiovascular tissues. Physiol Rev 2009;89:481534.

90. Bender SB, Herrick EK, Lott ND, Klabunde RE. Diet-induced obesity and diabetes reduce coronary responses to nitric oxide due to reduced bioavailability in isolated mouse hearts. Diabetes Obes Metab 2007;9:688-96.

91. Gruber HJ, Mayer C, Mangge H, Fauler G, Grandits N, WildersTruschnig M. Obesity reduces the bioavailability of nitric oxide in juveniles. Int J Obes 2008;32:826-31.

92. Perez-Martinez P, Alcala-Diaz JF, Delgado-Lista J, Garcia-Rios A, Gomez-Delgado F, Marin-Hinojosa C, et al. Metabolic phenotypes of obesity influence triglyceride and inflammation homoeostasis. Eur J Clin Invest 2014;44:1053-64.

93. Zeng NF, Mancuso JE, Zivkovic AM, Smilowitz JT, Ristenpart WD. Red blood cells from individuals with abdominal obesity or metabolic abnormalities exhibit less deformability upon entering a constriction. PLoS One 2016;11:1-12.

94. Cao J, Schwichtenberg KA, Hanson NQ, Tsai MY. Incorporation and clearance of omega-3 fatty acids in erythrocyte membranes and plasma phospholipids. Clin Chem 2006;52:2265-72.

95. Vidgren HM, Agren JJ, Schwab U, Rissanen T, Hänninen O, Uusitupa MI. Incorporation of n-3 fatty acids into plasma lipid fractions, and erythrocyte membranes and platelets during dietary supplementation with fish, fish oil, and docosahexaenoic acid-rich oil among healthy young men. Lipids 1997;32:697705 .

96. Brigandi SA, Shao H, Qian SY, Shen Y, Wu BL, Kang JX. Autistic children exhibit decreased levels of essential fatty acids in red blood cells. Int J Mol Sci 2015;16:10061-76.

97. Amézaga J, Arranz S, Urruticoechea A, Ugartemendia G, Larraioz A, Louka M, et al. Altered red blood cell membrane fatty acid profile in cancer patients. Nutrients 2018;10:1-13.

Received for publication: 10 November 2019. Accepted for publication: 7 January 2020.

This work is licensed under a Creative Commons Attribution-NonCommercial 4.0 International License (CC BY-NC 4.0).

(C) Copyright: the Author(s), 2020

Licensee PAGEPress, Italy

European Journal of Histochemistry 2020; 64:3081

doi:10.4081/ejh.2020.3081 